\title{
Electricity generation, desalination and microalgae cultivation in a biocathode-microbial desalination cell
}

\author{
Morvarid Khazraee Zamanpour, Hamid-Reza Kariminia*, Manouchehr Vosoughi \\ Department of Chemical and Petroleum Engineering, Sharif University of Technology \\ P.O. Box 11155-9465, Azadi Ave., Tehran, Iran
}

*Corresponding author.

Tel. \& Fax: +98 2166166426

Email: kariminia@sharif.ir 


\section{Abstract}

Recently, microalgae has received a high attention for application in bioelectrochemical systems due to its potential to be used for oxygen generation and biodiesel production. In this study performance of algal biocathode in a microbial desalination cell (MDC) was evaluated against air cathode and compared with that in a microbial fuel cell (MFC). Effluent of a dairy wastewater treatment plant with COD of $1000 \mathrm{mg} \mathrm{l}^{-1}$ was utilized as substrate in the anode and the microalgae Chlorella vulgaris was inoculated in the cathode using a synthetic culture media. Experiments were conducted using two different saline water concentrations including $15 \mathrm{~g} \mathrm{l}^{-1}$ (MDC-1) and $35 \mathrm{~g} \mathrm{l}^{-1}$ (MDC-2) in a desalination cell and produced power density, salt removal rate and algae growth were monitored. Maximum power density of $20.25 \mathrm{~mW} \mathrm{~m}^{-2}$ was observed in MDC-2 which was over two-times higher than that for MDC-1. This indicates the positive effect of using more concentrated saline solution on power generation due to higher conductivity and less internal resistance in the middle chamber. Moreover, salinity removal rate of $0.341 \mathrm{~g} \mathrm{l}^{-1}$ day $^{-1}$ in MDC-2 (1.5 times higher than MDC-1) as well as higher algal growth (38\%) in MDC-2 proved the higher performance of the MDC when more concentrated saline solution was used. Maximum power density generated by MDC-2 was comparable to that for MFC with air cathode (19.80 $\mathrm{mW} \mathrm{m}^{-2}$ ), however the MDC used in this work has the advantage of simultaneous saline removal and algae growth in a bioelectrochemical system.

Key words: biocathode; Chlorella vulgaris; desalination; microbial desalination cell; power generation

\section{Introduction}

Today, due to the growing population, the problem of water deficit has turned to a global and serious crisis (Greenlee et al. 2009). Accordingly, desalination of sea water or salty groundwater in many parts of the world is considered as a solution to this problem. Water desalination methods such as thermal procedure, reverse osmosis, and electro dialysis are currently considered as costly methods because of 
the provision of equipment and energy consumption (Gude 2011). Therefore, there is a need for more economical desalination technologies. Microbial desalination cell (MDC) is considered as a new technology for desalination of salt water (Cao et al. 2009). Its advantage over other prevalent methods is that in this bioelectrochemical system, separation of salt from water is accompanied by bio-electricity production and wastewater treatment by application of microorganisms in an integrated system, instead of using energy to separate salt from water (Gude et al. 2013). This system is based on the microbial fuel cell structure and its function is also the same. However, in addition to cathode and anode chambers, there is an intermediary chamber between cathode and anode that contains salt water which is separated from anode by an anion exchange membrane (AEM) and cathode by a cation exchange membrane (CEM) (Kim and Logan 2013). Anaerobic treatment of organic material in the anode is proceeded by microorganisms that lead to the production of electron, proton and carbon dioxide (Lee et al. 2008). Electrons are generated in the anode and transferred to the cathode via an external circuit. The unbalanced ionic charge in the cathode, because of exceeding amount of electron and the generation of electrons in the anode treats like propulsion for disintegrating ionic compounds in the salt water. Consequently, cations and anions migrate to the cathode and anode chambers, respectively through the ion exchange membranes that ultimately result in desalination of water in the middle chamber (Kim and Logan 2013). Saline water concentration in the middle chamber and substrate concentration utilizing by anaerobic microorganism in anode are two important factors in microbial desalination cells. Higher saline water and substrate concentration increases the power generation and overall conductivity of the system which resultes in more ion transport to anode and cathode from the middle chamber (Mehanna 2010).

Different MDC structures have been studied over the past few years. Microbial osmosis desalination cell (MODS) has been constructed by replacing AEM by an osmosis membrane. In a MODS, ions transfer across the membranes and water from anode chamber can also transport to saline water due to higher osmosis pressure in this middle chamber. Despite dilution of saline water in the middle chamber, lack of 
selectivity of osmosis membrane causes transport of undesirable ions affecting the performance of the system (Zhang et al. 2012). Stacked microbial desalination cell is another MDC structure that is constructed by series of AEM and CEM pairs that convert one saline water chamber to series of smaller ones. This desalination cell can remove $98 \%$ of salt from saline water (Chen et al. 2011). Bipolar MDC is constructed by bipolar membrane (overlaid selective layers of AEM and CEM) placed next to the anode AEM and CEM (A Carmalin et al. 2016). The extra chamber between anode and saline water avoid $\mathrm{Cl}^{-1}$ transport to anode and consequently $\mathrm{pH}$ reduction in this chamber. Therefore, accumulation of $\mathrm{Cl}^{-1}$ and $\mathrm{H}^{+}$in this chamber results in acid production in the cell (Chen S 2012).

Unlike conventional aerobic and anaerobic wastewater treatment methods that utilize a large amount of energy, a MDC uses the covert energy of organic material existing in wastewater to generate energy (Shizas and Bagley 2004). Ferricyanide as a powerful oxidant and oxygen are usually employed in the cathode chamber. However, ferricyanide is an expensive material that has an inverse effect on water quality. On the other hand, provision of enough dissolved oxygen in the catholyte demands aeration that itself needs energy consumption (Forresteal et al. 2012). Therefore, application of biocathode is an alternative choice to tackle these drawbacks. Easy access to the microalgae Chlorella vulgaris and its important role and high efficiency in eliminating carbon dioxide and oxygen production has made it a suitable choice as a biological provider of oxygen in the cathode (Powell et al. 2009). The microalgae use carbonaceous material such as bicarbonate and carbon dioxide to produce oxygen in the presence of light. The produced oxygen can be at the saturation level under suitable condition.

Even though, application of algal biocathode in MFC has been studied widely in recent years (Saeed et al. 2015, Sevda et al. 2015), algal MDC is a new approach towards environmentally sustainable and economically viable desalination and bio-energy generation method. To the best of our knowledge, there are few published studies on the application of algal biocathode in MDC (Kokabian et al. 2013, 2015). Microalgae Chlorella vulgaris is the most common biocathode that has been employed in MFC and 
MDC studies. High efficiency in both biodiesel production and converting carbon dioxide into oxygen in a wide range of illumination condition have made it a preferable choice for biocathode. In this study, we investigate the performance of algal cathode MDC using dairy wastewater, in two different $\mathrm{NaCl}$ concentrations compared with algal MFC, in order to study the effect of saline water concentration in the middle chamber and desalination mechanism on algal MDC performance. The dairy wastewater was used as anolyte, contained lactose, casein, protein and lipid that are biologically treated in the anode and consequently enhance bioelectricity production (Ashish and Sahu 2014). This wastewater, due to its low electrical conductivity compared to synthetic wastewater, can promote the desalination in the MDC (Luo et al. 2012). In the current study, attempts were made to study simultaneous desalination of salt water and generation of bioelectricity in a microbial desalination cell using the microalgae Chlorella vulgaris as biocathode.

\section{Methods and Materials}

\subsection{MFC and MDC configuration}

The MFC reactor consisted of two Plexiglas anode and cathode chambers, $175 \mathrm{ml}$ each. These two chambers were separated by a cation exchange membrane (CEM) with an active surface area of $6.25 \mathrm{~cm}^{2}$. The MDC reactor was made of 3 Plexiglas chambers, $175 \mathrm{ml}$ each. A CEM between the cathode and the desalination chamber, and an anion exchange membrane (AEM) between the anode and the desalination chamber, separated the three compartments. A graphite sheet with the active surface area of $16 \mathrm{~cm}^{2}$ was employed as anode and a 100 mesh stainless steel grid with the apparent surface area of $38 \mathrm{~cm}^{2}$ was used as cathode. Schematic of the microbial desalination cell is exhibited in Fig. 1. 


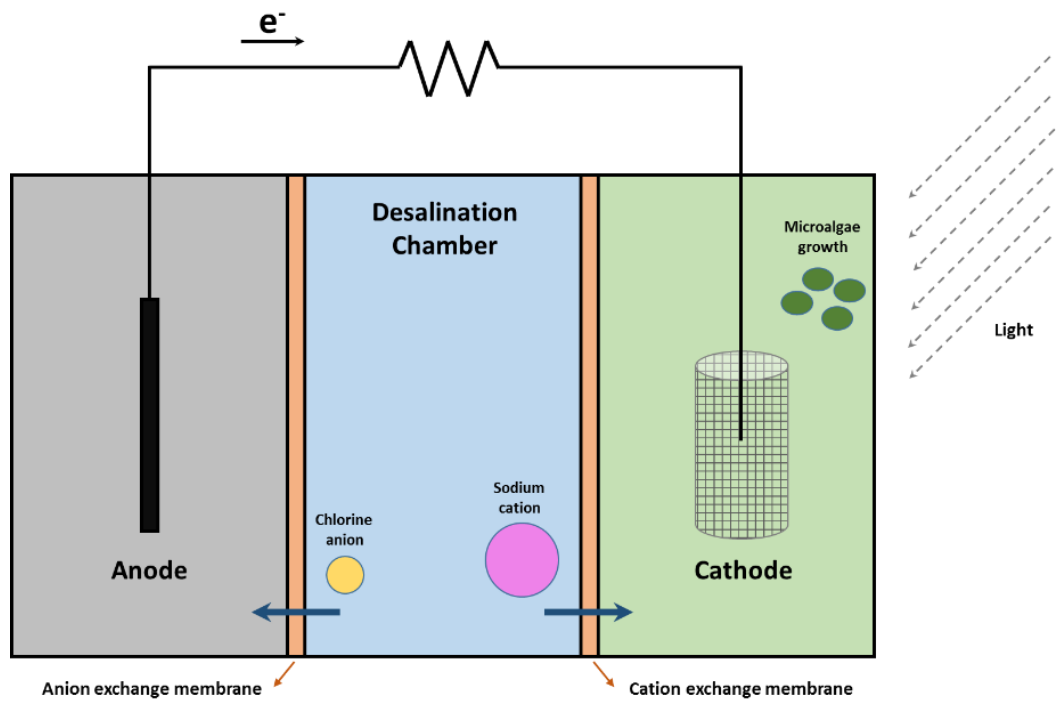

Fig. 1.Schematic of microalgae biocathode in microbial desalination cell.

\subsection{Microorganisms and microalgae}

Anode was inoculated with a microbial consortium collected from an upflow anaerobic sludge blanket reactor of a dairy wastewater treatment plant (Iran Dairy Industries Co., Tehran, Iran). The effluent of stabilization pond of this wastewater treatment plant was used as substrate in both the MFC and MDC reactors. As Table 1 demonstrates, lipid and suspended solid content of the anode inlet were measured 160-300 $\mathrm{mg} \mathrm{l}^{-1}$ (by standard Soxhlet extraction method) and 100-200 $\mathrm{mg} \mathrm{l}^{-1}$ (Filtration method), respectively (APHA 2014). The microbial inoculum and the wastewater were introduced to the anode in 1:1 ratio. The COD concentration of anolyte in both the MFC and MDC was $1000 \mathrm{mg} \mathrm{l}^{-1}$. 
Table 1. Characteristics of the dairy wastewater

\begin{tabular}{ll}
\hline COD & $1000 \mathrm{mg} \mathrm{l}^{-1}$ \\
$\mathrm{pH}$ & 7.5 \\
Lipid & $160-300 \mathrm{mg} \mathrm{l}^{-1}$ \\
Suspended solid & $100-200 \mathrm{mg} \mathrm{l}^{-1}$ \\
\hline
\end{tabular}

The microalgae Chlorella vulgaris (obtained from Microbial Bank of Materials and Energy Research Center, Alborz, Iran) was grown in the cathode chamber using the medium shown in Table 2. Cathode chamber contained $50 \mathrm{mM}$ PBS buffer $\left(4.58 \mathrm{~g} \mathrm{Na}_{2} \mathrm{HPO}_{4} \mathrm{l}^{-1}, 2.45 \mathrm{gNaH}_{2} \mathrm{PO}_{4} \cdot \mathrm{H}_{2} \mathrm{O} l^{-1}, 0.31 \mathrm{~g} \mathrm{NH}_{4} \mathrm{Cl} \mathrm{l}^{-1}\right.$ and $0.13 \mathrm{~g} \mathrm{KCl} \mathrm{l}^{-1}$ ) (Mehanna et al. 2010). In the MDC system, the middle desalination chamber contained $\mathrm{NaCl}$ solution of $15 \mathrm{~g} \mathrm{l}^{-1}$ or $35 \mathrm{~g} \mathrm{l}^{-1}$. Both systems operated at ambient temperature of $25 \pm 3^{\circ} \mathrm{C}$.

Table 2. C. vulgaris culture media used in the cathode (del Campo et al. 2013)

\begin{tabular}{ll}
\hline Compound & mg l$^{-1}$ \\
\hline $\mathrm{K}_{2} \mathrm{HPO}_{4}$ & 50 \\
$\mathrm{KH}_{2} \mathrm{PO}_{4}$ & 75 \\
$\mathrm{NH}_{4} \mathrm{Cl}$ & 75 \\
$\mathrm{CaCl}_{2}$ & 12.5 \\
$\mathrm{EDTA}$ & 25 \\
$\mathrm{NaHCO}_{3}$ & 65 \\
$\mathrm{MgSO}_{4} \cdot 6 \mathrm{H}_{2} \mathrm{O}$ & 25 \\
$\mathrm{FeSO}_{4} \cdot 7 \mathrm{H}_{2} \mathrm{O}$ & $11.3 \times 10^{-3}$ \\
$\mathrm{ZnSO}_{4} .7 \mathrm{H}_{2} \mathrm{O}$ & $11.7 \times 10^{-3}$ \\
$\mathrm{MnCl}_{2} \cdot 4 \mathrm{H}_{2} \mathrm{O}$ & $9.1 \times 10^{-3}$ \\
$\mathrm{CuCl}_{2} \cdot 2 \mathrm{H}_{2} \mathrm{O}$ & $8.0 \times 10^{-3}$ \\
$\mathrm{CoCl}_{2} \cdot 6 \mathrm{H}_{2} \mathrm{O}$ & $3.5 \times 10^{-3}$ \\
$\mathrm{NiCl}_{2} \cdot 6 \mathrm{H}_{2} \mathrm{O}$ & $1.8 \times 10^{-3}$ \\
\hline
\end{tabular}




\subsection{Analysis}

Voltage (V) over a $5 \mathrm{k} \Omega$ external resistance was measured by a digital Multi-Meter (PC Link 500a, Japan) Current (I) and power (P) were determined according to $\mathrm{V}=\mathrm{R}$ ext $\mathrm{I}$ and $\mathrm{P}=\mathrm{VI}$. Columbic efficiency (CE) \% was calculated as follows:

$C_{E}=\frac{8 \int_{0}^{t b} I . d t}{F \cdot V \cdot \Delta C O D}$

Polarization curves were obtained by replacing the external resistance in the range of $820 \mathrm{M} \Omega$ to $4 \Omega$. Conductivity of saline solutions was measured by an electro-conductivity meter (HQ14d Portable Conductivity Meter,HACH, USA). The $\mathrm{pH}$ of solutions was measured by $\mathrm{pH}$ meter (pH 3110 SET 12AA111, WTW, Germany). The growth of microalgae in the cathode chamber was continuously monitored by measuring the optical density of the medium at $680 \mathrm{~nm}$ using a spectrophotometer (CamSpec M501, UK). COD of the anolyte was measured according to standard methods (APHA 2014).

\section{Results and discussion}

\subsection{Effect of microalgae biocathode on MFC performance}

In order to determine the effect of microalgae biocathode on desalination and performance of the MDC in terms of energy generation, an air-cathode MFC operation was considered as a reference.

In the air-cathode MFC after acclimation of the anode in an open circuit phase and achieving a maximum voltage, the circuit was closed using a $5 \mathrm{k} \Omega$ external resistance. The maximum voltage of $339 \mathrm{mV}$ was stable for about 10 days for the air-cathode. However, in the MFC with algal biocathode, the voltage was at a lowest level for about 18 days and reached the maximum value of $313 \mathrm{mV}$ on day 29. In the MFC with air-cathode, oxygen is available at a saturated level which can proceed the reduction reaction in the cathode. Due to selectivity and fine pores of the CEM, amount of oxygen that could seep into the anode chamber is negligible. Therefore, the anode was operated under anaerobic condition. In the 
algal cathode-MFC, depletion of oxygen concentration in the cathode chamber occurs at the first day of the cycle, and also biofilm formation on the surface of the anode and cathode electrodes causes a delay in voltage evolution and delayed stability of the system. Comparing the voltage profile of these two MFC systems leads to conclude that the most significant limitation in algae cathode MFC is the long adaptation period required to act as a biocatalyst in the electron accepting process. Moreover, Comparing microalgae growth curve and voltage profile of algal cathode MFC (Fig. 2 (a), (b)) demonstrates that increase in voltage coincided with the log phase of microalgae growth, so the significant role of algae as electron acceptor is observed. In the air-cathode MFC, maximum produced power density was $19.8 \mathrm{~mW}$ $\mathrm{m}^{-2}$ but in algae cathode MFC, power density reduced to $12.91 \mathrm{~mW} \mathrm{~m}^{-2}$. Despite bioelectricity output reduction in algae cathode $\mathrm{MFC}$, high rate of algae growth in cathode can be considered as another green and renewable source of bio-energy in this system. According to optical density measurements, optical density increased from 0.2 to 1.6 in the cathode which is equivalent to $80 \mathrm{mg}^{-1}$. This was significantly higher than that which was obtained in previous studies. del Campo et al. observed $50 \mathrm{mg} \mathrm{l}^{-1}$ increase in algae concentration over 30 days in a MFC with carbon cloth cathode using an identical growth culture with our system (del Campo et al. 2013). Hence, it could be concluded that stainless steel grid provides more favorable growth condition for microalgae.

High growth rate of microalgae in this system can be a promising step towards achieving an integrated bioenergy production microbial fuel cell considering the lipid content of the microalgae as feedstock for biodiesel production. Even though in this experiment, due to small volume of biocathode, lipid extraction and measurement was not possible, we estimated the amount of stored energy in the algae cells by a theoretical yield equation (Asmare et al. 2013) to be about $3.125 \mathrm{~W} \mathrm{~m}^{-2}$ (anode area) which exceeds the air-cathode MFC's power density. It would be worthwhile to further study the design of an algal cathode MFC for optimizing the lipid production in the cathode chamber. In addition, based on successful algae 
growth in a MFC with dairy wastewater, evaluation of algal cathode performance in MDC with complementary desalination function at two different $\mathrm{NaCl}$ concentrations was studied.

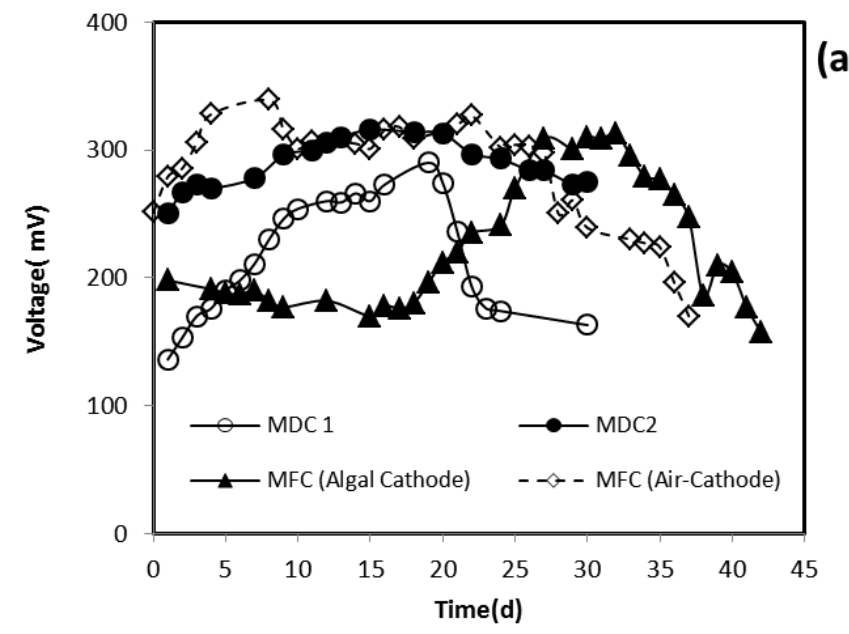

(a)
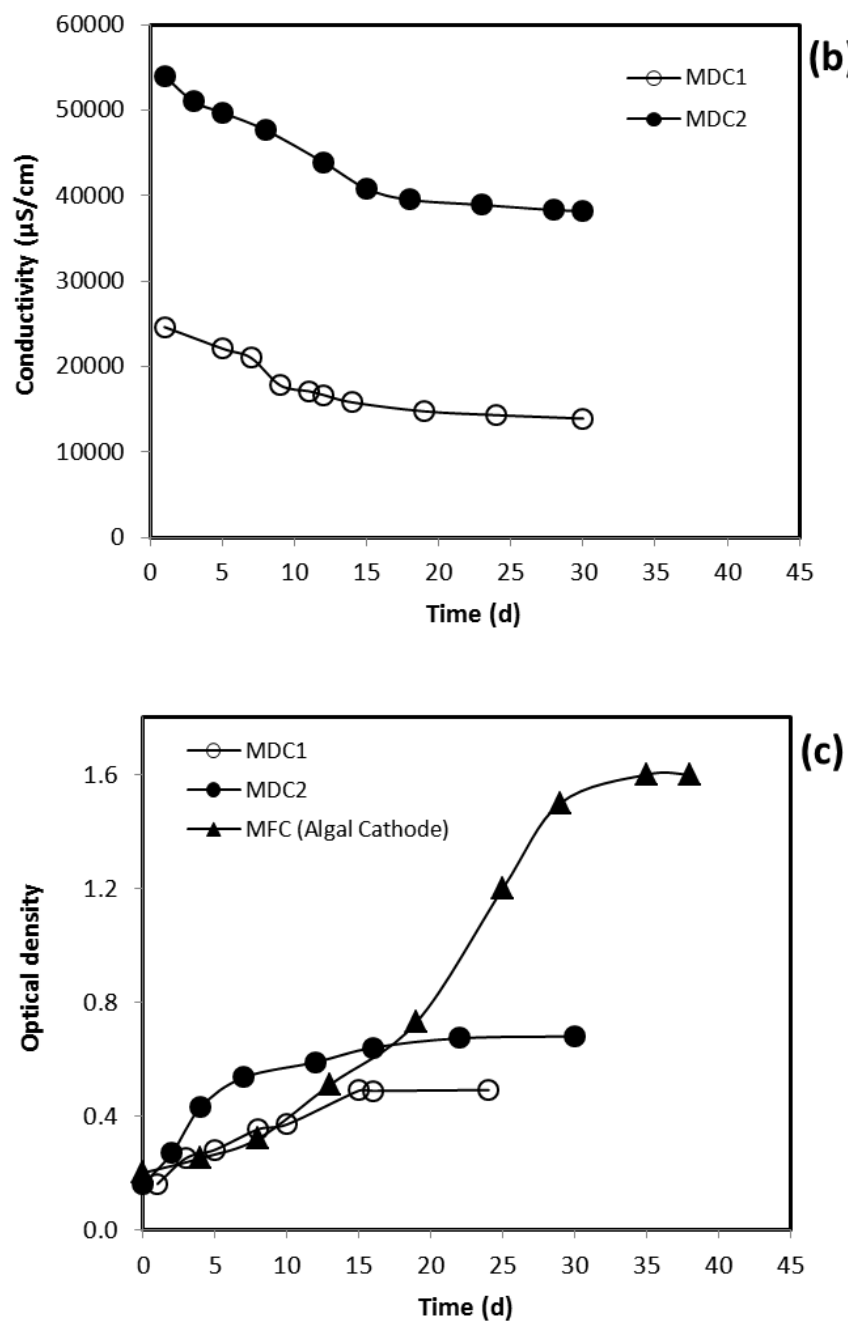
Fig. 2. (a) MFCs and MDCs performance with different types of cathode; (b) electrical conductivity in the middle chamber of MDCs; (c) growth of microalgae in MFC and MDC.

\subsection{Effect of salt concentration on algal MDC performance}

Although, chemical catholytes are not affected by desalination process, microorganims' function in anode chamber, such as anodic exoelectrogen bacteria are influenced by ion and electron transfer. Thus, determination of the most efficient condition for simultaneous algal biocathode MDC is the first step to introduce this system as a sustainable method for water desalination, wastewater treatment, and bioelectricity generation.

Previous studies on MDC have investigated diverse parameters such as saline water concentration and reactor configuration (chambers' volumetric ratio) on conventional MDCs' overall performance. In this study, we examined two saline water concentrations in an algal cathode MDC using equal volumes of anodic, cathodic and desalination chambers. As the voltage profiles and polarization curves of the two examined MDC systems indicated in Fig. 2(a) and Fig. 3(c),(d) show, MDC performance is strongly influenced by the salt concentration in the middle chamber. At the higher salt concentration $\left(35 \mathrm{~g} \mathrm{NaCl}^{-1}\right)$, enhanced voltage and power generation, as well as improved microalgae growth in the cathode chamber was observed. In MDC-2, higher salt concentration, increased the conductivity of the system where resulted in lower internal resistance. Based on two MDCs polarization curves (Fig. 3), when $35 \mathrm{~g} \mathrm{NaCl} 1^{-1}$ was placed in the middle chamber, the produced power density was $20.25 \mathrm{~mW} \mathrm{~m}^{-2}$ compared to 9.12 $\mathrm{mW} \mathrm{m} \mathrm{m}^{-2}$ in MDC with $15 \mathrm{~g} \mathrm{NaCl}^{-1}$. Desalination function in the MDC depends on the current generation (electron and ion transfer), so salinity removal rate in MDC-2 (with higher current generation) was $526 \mu \mathrm{S} \mathrm{cm}^{-1} \mathrm{~d}^{-1}\left(0.341 \mathrm{~g} \mathrm{l}^{-1} \mathrm{~d}^{-1}\right)$ compared to $356 \mu \mathrm{S} \mathrm{cm}^{-1} \mathrm{~d}^{-1}\left(0.214 \mathrm{~g} \mathrm{l}^{-1} \mathrm{~d}^{-1}\right)$ in MDC-1. At the end of MDC operation, saline concentration in MDC-2 and MDC-1 reached $24.5 \mathrm{~g}^{-1}$ and $8.5 \mathrm{~g} \mathrm{l}^{-1}$, respectively. In addition, based on conductivity measurements anolyte and catholyte conductivity increased in 
both MDCs. In MDC-2, anolyte conductivity increased from 2100 to $12200 \mu \mathrm{S} \mathrm{cm}^{-1} \mathrm{~d}^{-1}$ and in MDC-1, there was an increase up to $9800 \mu \mathrm{S} \mathrm{cm}^{-1} \mathrm{~d}^{-1}$. Migration of ions from the middle chamber i.e. $\mathrm{Cl}^{-}$to the anode and $\mathrm{Na}^{+}$to the cathode, is the main reason for this increase. Therefore, in MDC with higher current generation and ion transfer, more increase in anolyte and catholyte higher increasing conductivity rate was observed. $\mathrm{pH}$ value in the cathode of MFC changed from 7.5 to 7.8 , but in MDC's cathode due to higher concentration of hydroxyl and sodium ion, $\mathrm{pH}$ raised from 7.5 to 9.5 and 9 in MDC-2 and MDC-1, respectively. This $\mathrm{pH}$ raise resulted in lower algae growth in MDC compared to MFC. On the other hand, $\mathrm{pH}$ value of the anode of MFCs and MDC-1 dropped from 7.5 to 6.8. For MDC-2, the pH value dropped to 6.5. Accumulation of larger amount of protons and chlorine ion in the anode of MDCs resulted in lower $\mathrm{pH}$ values. Although, adding some buffer solutions can help the $\mathrm{pH}$ stability of the anode, high conductivity of these solutions might adversely affect the salt removal in the system. 

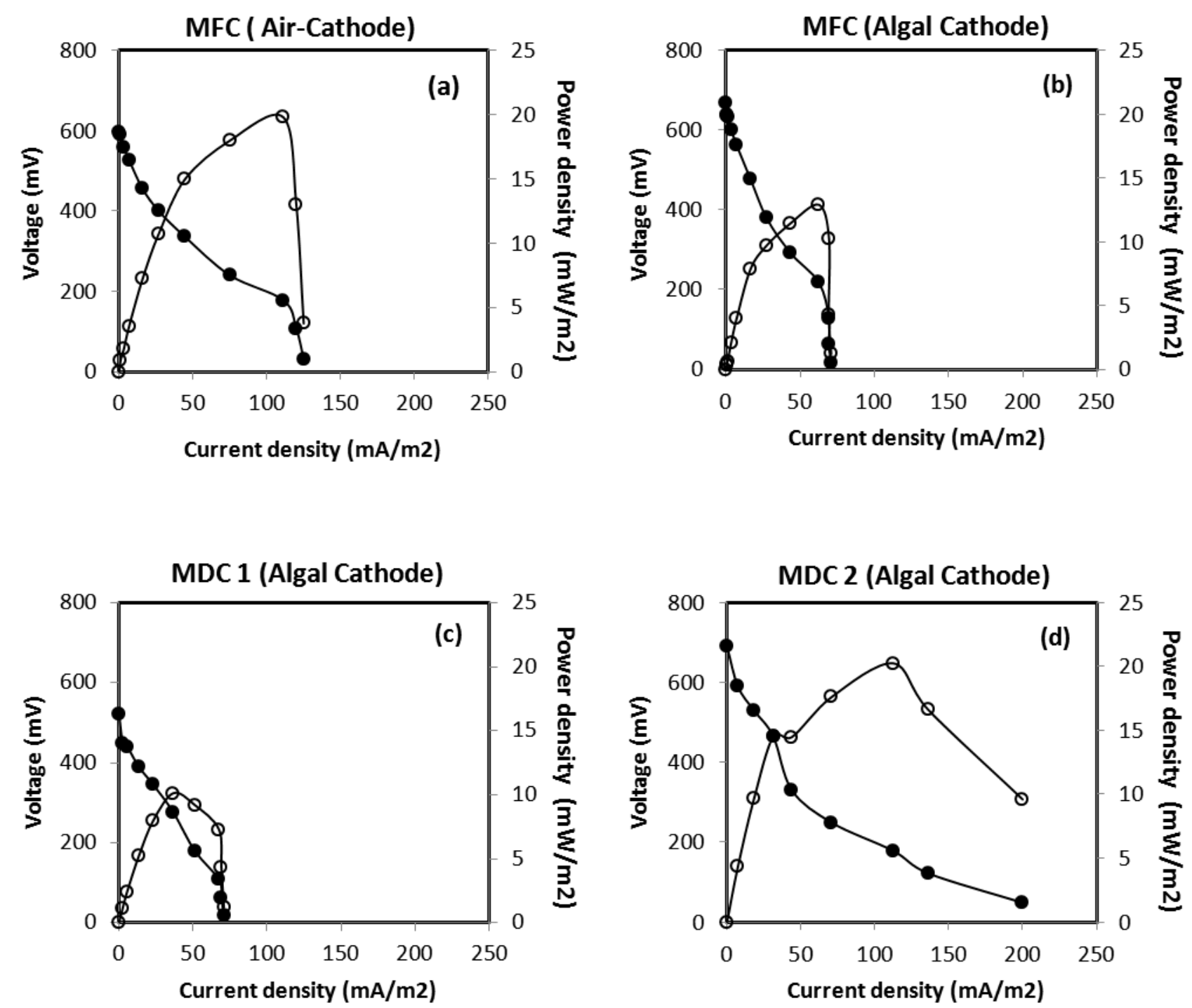

Figure 3. Polarization and power density curves of (a) MFC with air-cathode, (b) MFC with algal cathode, (c) MDC-1 ( $\mathrm{NaCl}$ concentration: $15 \mathrm{~g} \mathrm{l}^{-1}$ ), (d) MDC-2 ( $\mathrm{NaCl}$ concentration: $35 \mathrm{~g} \mathrm{l}^{-1}$ ).

Since all factors including electrodes, membranes, and initial concentration of anolyte and catholyte solutions in both MDC-1 and MDC-2 were identical, salt concentration and its impact on anode and cathode performance is the main reason for different performance between MDC-1 and MDC-2. Higher conductivity of middle chamber, anode and cathode, resulted in less internal resistance of MDC-2 (1885 
$\Omega$ ) compared to $3460 \Omega$ for MDC-1. Moreover, as the voltage profiles of two MDCs in Fig. 2(a) show, in MDC-1, voltage dropped more rapidly with a sharper slope compared to that for MDC-2. This could be due to higher internal resistance in MDC-1 since the conductivity of saline water dropped more rapidly. Even though Mehanna indicated that salt concentration didn't have significant effect on internal resistance and voltage generation of MDCs (Mehanna et al. 2010) in this MDC configuration and volume ratio of chambers (especially middle chamber to anode play an important role in the MDC performance), we can justify our results to be due to different electrodes distance and configuration. In our study, because of using a larger middle chamber, saline water conductivity had crucial effect on the MDC performance compensating for distance between the electrodes.

Fig. 2(b) shows optical density measurements for algae biocathode of both MDCs. In MDC-1, optical density increased from 0.16 to 0.490 and in MDC-2 it increased from 0.16 to 0.645 within 30 days. Algae growth rate was $5.5 \mathrm{mg} \mathrm{d}^{-1}$ and $8.1 \mathrm{mg} \mathrm{d}^{-1}$ in MDC-1 and MDC-2, respectively. Observing higher algae growth rate in MDC-2 as well as a higher current generation, proves that the phenomenon of more electron transfer to the cathode chamber positively affects algae growth. Since algae demands electron for reproduction through its metabolism, access to more electrons can enhance its growth as our results show.

Comparing voltage profiles and polarization curves of MDC-2 and MFC with air-cathode in Fig. 1(a) and Fig. 2(a), (d) shows approximately the same maximum power output and voltage, despite more electrodes distance in the MDC-2. In contrary to our findings, some other research results, report a poorer performance for MDC compared to MFC (Gude et al. 2013). Based on our observation, the MDC with $35 \mathrm{~g} \mathrm{NaCl}^{-1}$ in the middle chamber produced a power density about $60 \%$ higher than that for the MFC with algal cathode and approximately equal power density to that for the MFC with air-cathode. This shows that the high conductivity of saline solution promotes bioelectrochemical mechanism in the MDC. On the other hand, in the MDC with $15 \mathrm{~g} \mathrm{NaCl}^{-1}$, the produced power density was $20 \%$ lower 
than the power density produced by the MFC with algal cathode. This could be attributed to the farther electrodes distance in the MDC configuration.

The longer lag phase in the voltage profile of MFC with algal cathode in comparison with MDC-1 and MDC-2 can be explained as being due to the lack of higher oxygen concentration and slower rate of oxygen reduction reaction in the cathode chamber at the beginning of the batch cycle in the algal cathode MFC. Anode performance is adversely influenced by proton accumulation in this chamber. In the MDCs, the middle desalination chamber reduces the interaction between anode and cathode compartments where is no direct ion transfer from anode to cathode. Therefore, low perfromance of the cathode at the beginning of the cycle had less negative impact on the anode and the overall system performance. Besides, based on our results, in the MDCs, a higher potential differences between the middle chamber, the anode chamber with industrail wastewater, and the cathode chamber can ficiliate ion transfer and enhance current generation, compared with a MFC with approximately the same initial electrical conductivity for anode and cathode.

As Fig. 2(b) shows, a significant reduction in algae growth in the MDCs was observed. In the MFC, optical density of algae changed from 0.24 to 1.5 , and growth rate of algae was $18.4 \mathrm{mg} \mathrm{d}^{-1}$ compared to 8.1 $\mathrm{mg} \mathrm{d}^{-1}$ for MDC-2. One of the factors which may have adversely affected algae growth in the cathode of the MDC is the existence of sodium and hydroxyl ions in the cathode chamber.

\section{Conclusion}

This study has shown that simultaneous desalination, electricity generation and microalgae growth can be accomplished using a microbial desalination cell technology. However, application of algal biocathode in a microbial fuel cell reduced the amount of accessible oxygen in the cathode and consequently the generated power density dropped from $19.8 \mathrm{~mW} \mathrm{~m}^{-2}$ to $12.91 \mathrm{~mW} \mathrm{~m}^{-2}$. This is while, the MDC with 
higher salt concentration $\left(35 \mathrm{~g} \mathrm{NaCl}^{-1}\right)$ generated a power density of $20.25 \mathrm{~mW} \mathrm{~m}$. The superior performance of MDC with $35 \mathrm{~g} \mathrm{NaCl}^{-1}$ compared to microbial fuel cell and MDC with $15 \mathrm{~g} \mathrm{NaCl}^{-1}$ can be explained by the fact that saline water concentration has a role in controlling the internal resistance and conductivity of the system. Moreover, salt removal rate of $0.341 \mathrm{~g} \mathrm{l}^{-1} \mathrm{day}^{-1}$ achieved in the MDC with $35 \mathrm{~g} \mathrm{NaCl}^{-1}$ compared to that for the MDC with the concentration of $15 \mathrm{~g} \mathrm{NaCl}^{-1}\left(0.241 \mathrm{~g} \mathrm{l}^{-1}\right.$ day $^{-1}$ ) shows the essential effect of higher conductivity in the middle chamber on the system efficiency. Although, accumulation of sodium and hydroxyl ions in the cathode of MDC has negative impact on algae growth in the last days of the batch cycle, using a series of MDCs with algal biocathode and high saline concentration in the middle chamber, running in a shorter batch cycle seems to be an efficient way for the purpose of partial salt removal and lipid production.

Acknowledgements Authors would like to acknowledge Iran National Science Foundation (INSF) and research office of Sharif University of Technology for their financial support.

\section{References}

A. Carmalin Sophia, V.M. Bhalambaal, Eder C. Lima, M. Thirunavoukkarasu (2016) Microbial desalination cell technology: Contribution to sustainable waste water treatment process, current status and future applications, Journal of Environmental Chemical Engineering 4 3468-3478

APHA, (2014) Standard Methods for the Examination of Water and Wastewater, American Public Health Association, Washington, DC.

Ashish T, Sahu O (2014) Study of characteristics and treatments of dairy industry waste water. J Appl Environ Microbiol 2:16-22. 
Asmare AM, Demessie BA, Murthy GS (2013) Theoretical estimation the potential of algal biomass for biofuel production and carbon sequestration in Ethiopia. Int J Renewable Energy Res 3:560-570..

B. Zhang, Z. He (2012) Integrated salinity reduction and water recovery in an osmotic microbial desalination cell, RSC Adv. 2,3265-3269.

Cao X, Huang X, Liang P, Xiao K, Zhou Y, Zhang X, Logan BE (2009) A new method for water desalination using microbial desalination cells. Environ Sci Technol 43:7148-7152.

Chen S, Liu G, Zhang R, Qin B, Luo Y (2012) Development of the microbial electrolysis desalination and chemical-production cell for desalination as well as acid and alkali productions. Environ Sci Technol 46: 2467-2472.

del Campo G, Cañizares P, Rodrigo MA, Fernández FJ, Lobato J (2013) Microbial fuel cell with an algae-assisted cathode: A preliminary assessment. J Power Sources 242:638-645.

Forrestal C, Xu P, Ren Z (2012) Microbial desalination cell with capacitive adsorption for ion migration control. Bioresour Technol 120:332-336.

Greenlee LF, Lawler DF, Freeman BD, Marrot B, Moulin P (2009) Reverse osmosis desalination: water sources, technology, and today's challenges. Water Res 43:2317-2348.

Gude VG (2011) Energy consumption and recovery in reverse osmosis. Desalination and water treatment 36: 239-260.

Gude VG, Kokabian B, Gadhamshetty V (2013). Beneficial bioelectrochemical systems for energy, water, and biomass production. J Microb Biochem Technol S6-005.

Kim Y, Logan BE (2013) Microbial desalination cells for energy production and desalination. Desalination 308:122-130. 
Kokabian B, Gude VG (2013) Photosynthetic microbial desalination cells (PMDCs) for clean energy, water and biomass production. Environ Sci 15:2178-2185.

Kokabian B, Gude VG (2015) Sustainable Photosynthetic Biocathode in Microbial Desalination Cells Chemical Engineering Journal 262 958-965

Lee HS, Parameswaran P, Kato-Marcus A, Torres CI, Rittmann BE (2008) Evaluation of energyconversion efficiencies in microbial fuel cells (MFCs) utilizing fermentable and non-fermentable substrates. Water Res 42:1501-1510.

Luo H, Xu P, Roane TM, Jenkins PE, Ren Z (2012) Microbial desalination cells for improved performance in wastewater treatment, electricity production, and desalination, Bioresour Technol 105:60-66.

Mehanna M, Saito T, Yan J, Hickner M, Cao X, Huang X, Logan BE (2010) Using microbial desalination cells to reduce water salinity prior to reverse osmosis, Energy Environ Sci 3:1114-1120.

Powell EE, Mapiour ML, Evitts RW, Gordon AH (2009) Growth kinetics of Chlorella vulgaris and its use as a cathodic half cell. Bioresour Technol 100:269-274.

Saeed HM, Husseini GA, Yousef S, Saif J, Al-Asheh S, Fara AA, Azzam S, Khawaga R, Aidan A (2015) Microbial desalination cell technology: a review and a case study. Desalination, 359, 1-13.

Sevda S, Yuan H, He Z, Abu-Reesh IM (2015) Microbial desalination cells as a versatile technology: Functions, optimization and prospective. Desalination, 371:9-17.

Shizas I, Bagley DM (2004) Experimental determination of energy content of unknown organics in municipal wastewater streams. J Energy Eng 130:45-53. 
X. Chen, X. Xia, P. Liang, X. Cao, H. Sun, X. Huang (2011), Stacked microbial desalination cells to enhance water desalination efficiency, Environ. Sci. Technol. 45,2465-2470. 